\title{
ETNOTEKNOKONSERVASI PEMANFAATAN PALEM SEBAGAI BAHAN PEMBUATAN BUBU TRADISONAL SUKU MAYBRAT
}

\author{
(Ethno-techno-conservation in use of Palm as Raw Material Component for \\ Traditional Bubu of Maybrat Ethnic)
}

\author{
MARIA M. BASNA ${ }^{1}$, RUDI A. MATURBONGS ${ }^{2}$, ANTONI UNGIRWALU ${ }^{1 凶}$ \\ ${ }^{1}$ Jurusan Kehutanan, Fakultas Kehutanan Universitas Papua Manokwari, Papua Barat, 98314. \\ Tlp/Fax: +62986211065. \\ ${ }^{2}$ Sekolah Pascasarjana Universitas Papua, Jl. Gunung Salju Amban, Manokwari 98314 \\ $\square$ Penulis Korespondensi: Email: a.ungirwalu@unipa.ac.id \\ Diterima: 10 Mar 2020| Disetujui: 18 Apr 2020
}

\begin{abstract}
Abstrak. Pengetahuan tradisional dan kearifan lokal terkait dalam pemanfaatan sumberdaya alam hutan berkembang sebagai multi disiplin ilmu dalam kajian etnobiologi, etnoekologi, etnoforestri, sampai pada etnoteknokonservasi. Sayangnya dalam kajian etnobotani masih terdapat kesenjangan publikasi dalam mendokumentasikan aspek ekologi (biologi) dan budaya (sosial) di Papua terkait pengelolaan konservasi berbasis masyarakat. Oleh karena itu penting melakukan kajian terkait pendokumentasian pengetahuan konservasi berbasis masyarakat di Papua Barat. Tujuan kajian penelitian ini adalah mengkonstruksikan etnoteknokonservasi tumbuhan palem sebagai bahan pembuatan bubu tradisional oleh masyarakat suku Maybrat di Papua Barat. Hasil pelingkupan pengetahuan lokal pembuatan bubu dan teknik pembuatan sero suku Maybrat adalah bagian dari simbol kognitif yang tergolong dalam kecakapan hidup (life skill) individu dimana kondisinya sangat bergantung pada keadaan lingkungan tempat tinggal dan potensi sumberdaya hutan yang dimilikinya. Pemanfaatan tumbuhan palem sebagai sumberdaya alam dan proses konstruksi pengetahuan lokal pembuatan bubu tradisional sebagai wujud etnoteknokonservasi suku Maybrat berkaitan erat dengan mata pencaharian masyarakat sebagai nelayan aktif dan pasif. Pengetahuan lokal dalam pemanfaatan tumbuhan palem dalam proses pembentukannya tidak sekedar berdimensi kognitif semata, tetapi juga berdimensi nilai konservasi lokal dalam mempertahankan sistem penangkapan ikan yang ramah lingkungan dan berkelanjutan yang seharusnya perlu dipertahankan.
\end{abstract}

Kata kunci: Papua Barat, Maybrat, bubu, palem, etnoteknokonservasi

Abstract. Traditional knowledge and local wisdom related to the utilization of natural resources of the forest developed as a multi-disciplinary in the study of ethnobiology, ethnoecology, ethnoforestry, to ethno-conservation. Unfortunately, in ethnobotany studies there are publicity gaps in documenting ecological (biological) and cultural (social) aspects in Papua related to community-based conservation management. Therefore, it is important to conduct a study related to the documentation of communitybased conservation knowledge in West Papua. The purpose of this research study is to construct ethnonoconstruction of palm plants as material for making traditional bubu by the Maybrat tribe in West Papua. The results of scoping of local knowledge of bubu making and sero making techniques of the Maybrat are part of cognitive symbols that are classified as individual life skills where the conditions are highly dependent on the state of the environment in which they live and the potential of forest resources. The use of palm trees as natural resources and the local knowledge construction process of making traditional bubu as a manifestation of the Maybrat etnotecnoconservation are closely related to 
people's livelihoods as active and passive fishermen. Local knowledge in the use of palm trees in the process of its formation is not merely a cognitive dimension, but also the dimension of local conservation values in maintaining an environmentally friendly and sustainable fish capture system that should need to be maintained.

Keywords: West Papua, Maybrat, bubu, palm, etnotecnoconservation

\section{PENDAHULUAN}

Perkembangan etnobotani telah berevolusi dari disiplin ilmu utama yang awalnya terbatas pada kajian inventariasi tanaman ke upaya multidisiplin yang berfokus pada pemahaman hubungan antara tumbuhan dan manusia (Balick 1996). Sebelum pertengahan abad kedua puluh, etnobotani adalah subdisiplin ilmu antropologi. Konstruksi etnosains yang pertama kali diperkenalkan oleh Harold C. Conklin pada tahun 1955 selanjutnya tahun 1962 teori ini mendapat dukung oleh Charles O. Frake. Dalam perkembangnnya di tahun 1957 Ward Goodenough mencetuskan etnoekologi sebagai kajian antropologi berbasis bahasa.

Studi tentang interaksi manusia, keanekaragaman hayati, dan lingkungan adalah alat dasar untuk memahami faktor-faktor yang mengikat masyarakat dengan sumber daya alam (Albuquerque dkk. 2018). Pengelolaan sumber daya alam, termasuk tanaman oleh masyarakat, umumnya melibatkan aspek sosio-ekonomi dan sistem ekosistem terintegrasi, yang didasarkan pada sistem kepercayaan dan sistem pengetahuan (Barrera-bassols dan Toledo 2013). Terutama dalam memenuhi kebutuhan masyarakat di sekitar hutan berdasarkan pengetahuan tradisional, kearifan lokal, dan kepercayaan ekologis (Berkes 2009; Roslinda 2018; Dako et al. 2019). Pengetahuan tradisional dan kearifan lokal terkait dalam pemanfaatan sumberdaya alam hutan berkembang sebagai multi disiplin ilmu dalam kajian etnobiologi, etnoekologi, etnoforestri, sampai pada etnoteknokonservasi.

Dalam konteks ini, etnoteknokonservasi adalah bagian dari etnobotani dalam perspektif kajian multidisiplin ilmu yang menguhubungkan antara hubungan tumbuhan dan masyarakat lokal (ekologi-budaya) dengan pengetahuan tradisional tentang pemanfaatan SDA hutan berkelanjutan melalui praktek teknologi tradisional secara adaptif. Kehutanan yang berfokus pada ekologi-hutan (forestecology) dalam skala luas tentang pengelolaan SDA adalah sudah hal yang biasa. Tetapi pada skala lokal tentang etnoforestri yang terkait pada kognitif (pengetahuan) masyarakat lokal dan isu-isu lingkungan hidup merupakan sesuatu yang baru menjadi fokus pada beberapa dekade terakhir ini.

Pengetahuan lokal tentang kekayaan potensi dan pemanfaatan SDA sebagai sumber informasi penting yang digunakan dalam pengelolaan konservasi keanekaragaman hayati dan ekosistem semakin banyak mendapat pengakuan dari berbagai pihak (Joa et al. 2018). Sayangnya dalam kajian etnobotani terdapat kesenjangan publikasi dalam mendokumentasikan aspek ekologi (biologi) dan budaya (sosial) di Papua terkait pengelolaan konservasi berbasis masyarakat. Dapat dilihat dari didistribusi yang secara tidak merata di seluruh habitat dan budaya di Papua bahwa budaya yang tidak terancam punah menerima lebih banyak perhatian ilmiah dibandingka kajian yang terancam punah 
(Cámara-Leret et al. 2014; Cámara-Leret and Dennehy 2019). Belum lengkap dan tuntasnya pendokumentasikan secara ilmiah sebagai salah satu faktor hilangnya nilai-nilai kearifan lokal terkait pola pengetahuan konservasi.

Kelompok gerakan hijau terkenal dengan slogan "Think Globally and Act Locally" artinya berpikirlah secara global dan bertindaklah secara lokal. Hal ini tidak terlepas dari kritik dampak negatif pembangunan yang merubah tatanan dalam kehidupan masyarakat lokal, terutama degradasi kearifan lokal atau pengetahuan tradisional. Detradisionalisasi atau penghapusan terhadap tradisi dan adat kebiasaan masyarakat lokal diganti dengan tradisi atau kebiasaan baru yang dibawa dari luar masyarakat merupakan tantangan terbesar saat ini.

Maybrat sesungguhnya berasal dari kata Mai-Brat hasil kajian studi bahasa yang dilakukan Brown (1991) dalam proyek Summer Institute of Linguistics (SIL) bersama Universitas Cenderawasih. Bahasa Mai Brat adalah salah satu bahasa yang terbesar di Papua Barat khususnya masyarakat yang tinggal di keliling danau Ayamaru. Selanjutnya kelompok masyarakat ini berkembang menjadi alah satu kelompok suku besar di Papua Barat dan terbagi dalam 3 (tiga) sub-suku yaitu Ayamaru, Aitinyo dan Aifat. Kelompok Suku Maybrat mendiami daerah pedalaman Kepala Burung yang mencakup suatu bentangan wilayah dari tepian Timur Kamundan di Timur hingga ke Sun dan Waban di Barat; dari kaki Pegunungan Tambrauw di Utara hingga ke sekitar Danau Ayamaru di Selatan. Ketiga sub-suku ini memiliki satu budaya, bahasa dan adat-istiadat serta mata pencaharian yang sama.

Selain Mkah ora atau sistem berkebun secara tradisional, suku Maybrat juga memiliki mata pencaharian sampingan Mofot syoh/Maka aya atau menangkap ikan. Pemanfaatan dan praktek tradisional yang dilakukan masyarakat mempunyai hubungan yang sangat erat dengan lingkungan hutan sebagai sumber utama kebutuhan mendasar masyarakat. Pembangunan yang masif tanpa perencanaan yang baik telah banyak membentuk detradisionalisasi pengetahuan masyarakat terutama dalam praktek penangkapan ikan atau yang dikenal dengan sebutan "Mji Wata" berbahan dasar tumbuhan palem. Oleh karena itu kajian penelitian ini bertujuam mengkonstruksikan pengetahuan lokal etnoteknokonservasi tumbuhan palem sebagai bahan pembuatan bubu tradisional oleh masyarakat suku Maybrat di Papua Barat.

\section{METODE PENELITIAN}

Kajian ini merupakan bagian dari skrispi mahasiswa Fakultas Kehutanan Universitas Papua yang dilaksanakan di Kampung Mapura Distrik Ayamaru Utara Timur Kabupaten Maybrat pada tahun 2014. Subjek yang diamati adalah masyarakat tradisional Kampung Mapura yang memanfaatkan tumbuhan palem untuk membuat bubu dan objek yang diamati dalam penelitian ini adalah tumbuhan palem yang dimanfaatkan oleh masyarakat Kampung Mapura sebagai bahan baku pembuatan bubu.

Pengambilan Responden secara purposif dan acak sederhanan. Cara purposif digunakan untuk menentukan responden kunci berupa tokoh adat, kepala kampung dan tokoh agama. Dengan asumsi bahwa responden kunci tersebut dapat memberikan gambaran yang lebih jelas tentang informasi yang berkaitan dengan pemanfaatan palem sebagai bahan baku pembuatan bubu. Sedangkan dengan cara acak sederhana digunakan untuk menetukan responden contoh berupa kepala keluarga (KK) 


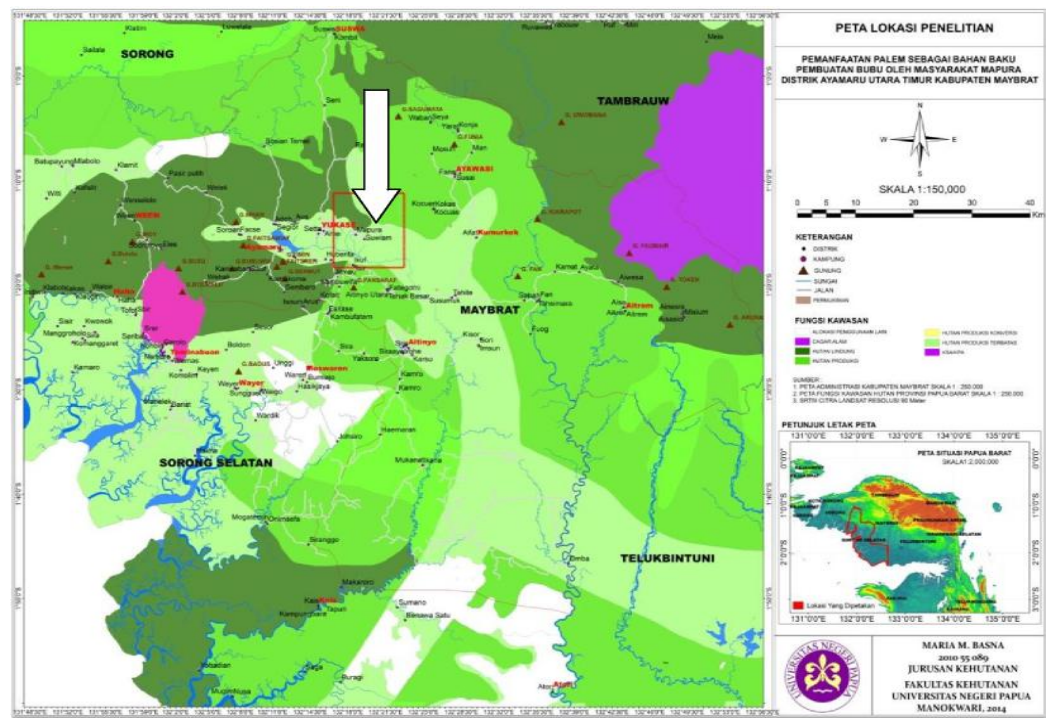

Gambar 1. Lokasi penelitan

yang berada di Kampung Mapura dengan memilih $\pm 10 \mathrm{KK}$ yang benar-benar memanfaatkan tumbuhan palem untuk membuat bubu.

Metode yang digunakan dalam penelitian ini adalah metode deskriptif dengan teknik observasi lapang. Metode deskriptif adalah produk pemecahan masalah yang diselidiki dengan menggambarkan atau melukiskan keadaan subyek atau obyek penelitian pada saat sekarang berdasarkan fakta-fakta yang tampak atau sebagaimana adanya. Teknik observasi lapang adalah observasi yang dilakukan dengan mencatat segala perilaku yang ditemukan di tempat kejadian.

Data yang dikumpulkan dibagi menjadi data primer dan data sekunder. Data primer diperoleh dengan wawancara dengan berpedoman pada daftar kuisioner yang telah disiapkan dan pengamatan lansung di lapangan. Sedangkan data sekunder diperoleh dari instansi dan publikasi yang berkaitan dengan penelitian ini. Selanjutnya data yang diperoleh berupa pengamatan dilapangan yang selanjutnya dianalisis secara deskrptif dan disajikan dalam bentuk tabel dan gambar yang menjelaskan tentang pola pemanfaatan palem untuk bahan baku pembutan bubu. Selanjutnya untuk mengkonstruksi etnoteknokoservasi dalam kajian elaborasi emik dan etik terkait dengan pengetahuan lokal suku Maybrat dalam mendeskripsikan lingkungan fisik terhadap proses pemanfaatan palem sebagai bahan baku pembuatan bubu tradisional seperti pada gambar 2 berikut.

Gambar 2. Konstruksi etnokonservasi pemanfaatan palem dalam pembuatan bubu tradisional
Etnoteknokonservasi

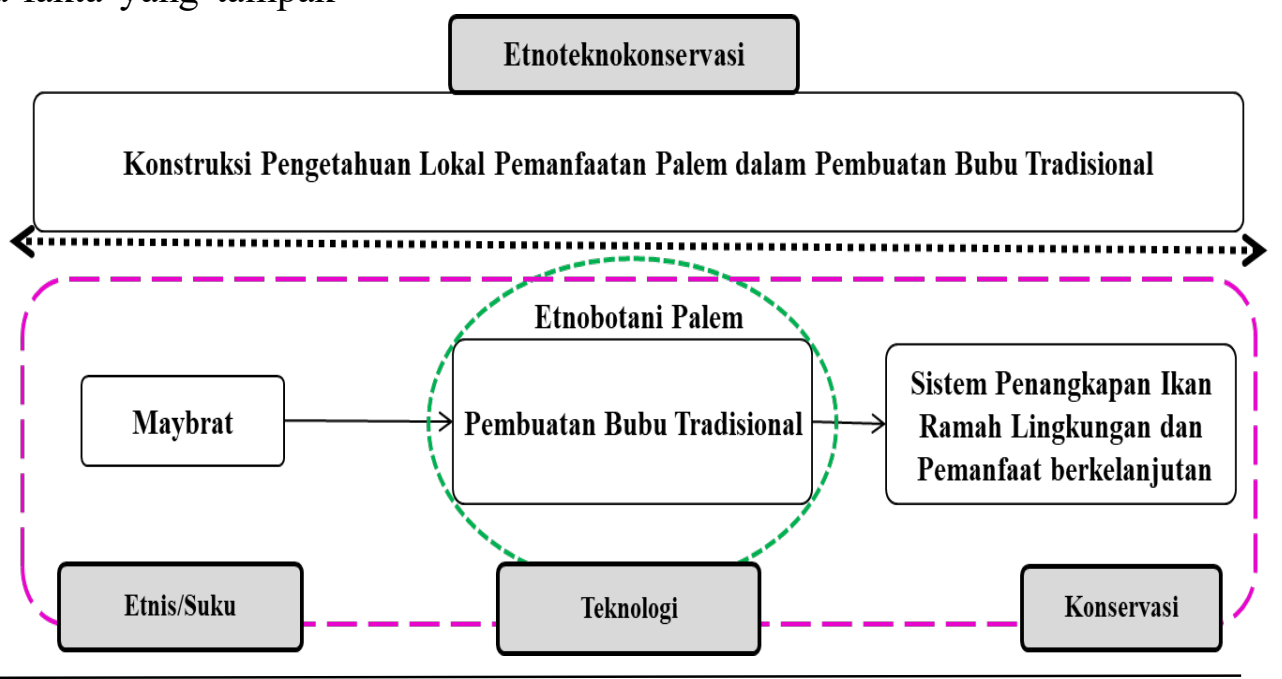

74

@ Asosiasi Peneliti Biodiversitas Papuasia-Fakultas Kebutanan UNIPA 


\section{HASIL DAN PEMBAHASAN}

Penelitian etnobotani di wilayah Papuasia yaitu wilayah yang mencakup Papua Barat (Iran Jaya), Papua New Guinea sampai Kepulauan Saloman sudah cukup banyak dilakukan (Forster 1993). Peneltian etnobotani yang komperhensif dilakukan Powell, (1976) berhasil mengungkapkan pememanfaatan tumbuhan sebagai bahan makanan, perhiasan, magis, obat-obatan, alat pemburu, memancing, upacara agama, kesenian, bahan alat seni, bahan baku pembuatan perahu dan rakit perkakas serta senjata oleh masyarakat asli di Papua Barat dan Papua New Guinea. Penelitian terbaru Cámara-Leret and Dennehy (2019) mengungkapkan dari 488 referensi yang diterbitkan antara tahun 1885 sampai 2018 terdapat 1070 spesies berguna endemik di Papua dan 720 spesies yang dimanfaatakan oleh masyarakat. Dari kajian tersebut dominasi pemanfaatan untuk spesies tumbuhan terbanyak berasal dari famili Arecaceae (palem-paleman) yaitu sebanyak 44 spesies.

Berbeda dengan penelitian etnobotani palem di Papua sebelumnya oleh Maturbongs dkk (1996), Rumbiak (2000), Asmuruf (2002), Mansai (2003) yang lebih banyak mengungkapkan pemanfaatan palem sebagai bahan konstruksi bangunan, obat-obatan, pangan, bahan bakar, kesenian dan mistik, perkakas dan ritual atau upacara adat. Pada kajian ini pemanfaatan tumbuhan palem sebagai salah satu fungsi pengetahuan konservasi dalam pembuatan bubu tradisional untuk kelestariaan sumberdaya alam dengan teknologi yang sangat ramah lingkungan dan membentuk pola pemanfaatan berkelanjutan secara turun-temurun oleh suku Maybrat. Kajian ini lebih mengutamakan kepentingan pendokumentasian budaya dalam konteks kelestarian sumber daya alam (Dharmono 2007).
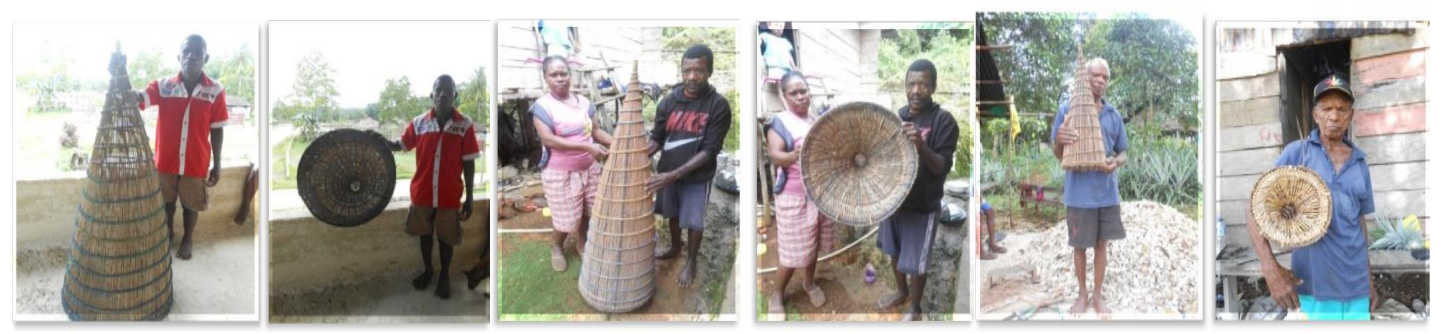

Gambar 3. Bubu tradisional suku Maybrat yang terbuat dari tumbuhan palem

Gambar 3. menunjukan konstruksi bentuk bubu tradisional suku Maybrat dengan tiga wujud berbeda, yaitu ukuran besar, sedang dan kecil. Ukuran tersebut menunjukan bahwa sejak dahulu suku Maybrat telah menggunakan alat tangkap tradisional yang ramah akan lingkungan sesuai dengan fungsi utamanya untuk menangkap ikan pada aliran sungai dan di danau Ayamaru secara berkelanjutan.
Bubu adalah alat perangkap ikan yang umumnya mempunyai satu atau dua pintu masuk dan dapat diangkat ke beberapa daerah penangkapan dengan mudah tanpa menggunakan perahu. Bubu merupakan alat tangkap pasif yang dibuat secara tradisional maupun modern sebagai perangkap ikan yang terbuat dari bahan dasar rotan, bambu, kawat, besi, jaring, kayu, kelambu atau plastik buat 
dengan teknik dan bentuk yang unik sehingga ikan yang masuk terperangkap dan sulit keluar. Batasan tradisioanl dalam penelitian ini adalah penggunaan peralatan atau benda yang sudah ada sejak zaman dahulu, bersifat sederhana, penggunaanya masih alami dan cenderung menggunakan tenaga manusia (Damayanti dan Syahrani 2018).

\section{Etnobotani Palem dalam Pembuatan Anyam Bubu Tradisional}

Tumbuhan palem sangat akrab dengan masyarakt suku Mabrat khususnya masyarakat yang berada pada seputaran DAS dan Danau Ayamaru. Berdasarkan hasil penelitian ditemukan 4 (empat) jenis/spesies palem dari 3 (tiga) genus dalam dua sub famili berbeda yaitu sub famili Arecoideae dan Calamoideae yang dimanfaatkan oleh masyarakat untuk pembuatan bubu tradisional seperti yang tersaji pada tabel 1. Berdasarkan tabel 1, keempat jenis palem yang dimanfaatkan oleh masyarakat suku Maybrat di Kampung Mapura untuk pembuatan bubu tradisional berasal dari habitat hutan alam di sekitar danau Ayamaru yang terdiri dari sub famili Arecoideae terdapat 1 (satu) jenis yaitu Hydriastele pinangoides Becc.W.J. Baker \& Loo. dan dari sub famili Calamoideae terdapat 3 (tiga) jenis yaitu Calamus interuptus Becc., Calamus keyensis Becc. dan Korthalsia zippelii Burr.

Tabel 1. Jenis-jenis palem yang dimanfaakan sebagai bahan baku pembuatan bubu

\begin{tabular}{lccccc}
\hline No & Sub Famili & Genus & Spesies & Nama lokal & Fungsinya \\
\hline 1. & Arecoideae & Hydriastele & $\begin{array}{c}\text { Hydriastele pinangoides } \\
\text { Becc. W. J. Baker \& Loo. }\end{array}$ & Srah & Rangka memanjang \\
2. & Calamoideae & Calamus & $\begin{array}{c}\text { Calamus interuptus Becc. } \\
\text { 3. Ses/Bomifra }\end{array}$ & Rangka spiral \\
3. & Calamoideae & Calamus & Calamus keyensis Becc. & Bofake & Rangka spiral \\
4. & Calamoideae & Korthalsia & Korthalsia zippellii Burr. & Hiyoh/Bosin & Tali Pengikat \\
\hline
\end{tabular}

Sumber: Basna, 2014

Secara taksonomi keempat jenis ini memiliki perbedaan baik morfologi berdasarkan klasifikasi ilmiah maupun dalam penamaan lokal terkait fungsi utama dalam pembuatan anyaman bubu tradisional dalam menyusun kerangka bubu berbentuk memanjang, melingkar (spiral) maupun berfungsi sebagai tali pengikat. Jenis Hydriastele pinangoides Becc. W. J. Baker \& Loo. memiliki perawakan tumbuhan sedang, berumpun, tegak, tinggi pohon 3-5 meter. Batang bentuk bulat silindris, diameter 2-3 cm, panjang ruas $5-15 \mathrm{~cm}$, arah tumbuh tegak, tekstur permukaan beralur, warna hijau waktu muda setelah tua berwarna coklat.

Jenis Calamus interuptus Becc. memiliki perawakan kecil, tunggal (soliter) dengan ciri memanjat. Batang memiliki panjang $46 \mathrm{~m}$, diameter 1-2 cm, panjang ruas $27-30 \mathrm{~cm}$, berwarna kecoklatan, tekstur permukaan berduri. Jenis Calamus keyensis Becc. memiliki perawakan tumbuhan tunggal, tipe tumbuh memanjat. Batang berbentuk bulat, berwarna hijau tua, panjang batang bebas pelepah $32 \mathrm{~m}$, diameter batang selang 10-21 mm, panjang ruas12-18 cm buah berbentuk bulat lonjong, berwarna putih, tidak bersisik, diameter buah 6 mm, jumlah 404 pada tiap tangkai buah. Sementara jenis Korthalsia zippelii Burr memiliki perawakan tumbuh secara berumpun dan memanjat karena memiliki alat pemanjat bentuknya sirus. Batang bentuknya bulat lonjong, berwarna coklat kemerahan, diameter 
selang antara $10-20 \mathrm{~mm}$, panjang $27 \mathrm{~m}$, panjang ruas $26-38 \mathrm{~cm}$

Dalam memahami lingkungan budaya suku Mabrat, pengungkapan taksonomi-taksonomi, klasifikasi-klasifikasi, terminologi-terminologi lokal sangat penting. Sebab dalam taksonotni, klasifikasi dan terminologi inilah terkandung pernyataan-pernyataan atau ide-ide masyarakat yang diteliti mengenai lingkungan budaya terkait penamaan lokal tanaman, khususnya tumbuhan palem berdasarkan pengetahun lokalnya.

Ditemukan 2 (dua) jenis pelem yang penamaan lokalnya lebih dari satu. Hal ini terkait dengan klasifikasi morfologi berdasarkan proses pembuatan bubu tradisional, untuk jenis Calamus interuptus Becc. dan Korthalsia zippelii Burr. Secara morfologi jenis palem yang tumbuhan menjalar di hutan untuk jenis Calamus interuptus Becc. masyarakat menyebutnya dengan nama lokal Ses, sementara untuk jenis Korthalsia zippelii Burr. dengan sebutan nama lokal Hiyoh. Terminilogi perubahan nama lokal kedua jenis palem ini berbeda setelah diambil proses pengambilan untuk digunakan sebagai bahan untuk pembuatan bubu. Masyarakat lokal menyebut nama lokal Ses sebagai Bomifra sementara nama lokal Hiyoh disebut sebagai Bosin. Berbeda dengan kedua jenis lainnya untuk penamaan yang konsisten pada Hydriastele pinangoides Becc.W.J. Baker \& Loo. dengan penyebutan nama lokal Srah dan Calamus keyensis Becc. dengan nama lokal Bofake, digunakan baik sebelum dan setelah diambil dari hutan maupaun saat pembuatan bubu tradisional.

Selain penamaan lokal untuk tumbuhan palem sebagai bahan dasar pembuatan bubu tradisional, dijumpai juga terminilogi alasan kuaat penggunaannya berdasarkan pengalaman yang telah dikuasai oleh masyarakat suku Maybrat secara turun-temurun. Jenis Hydriastele pinangoides Becc. W. J. Baker \& Loo. (Srah) merupakan satu-satunya bahan utama yang digunakan selain dalam pembuatan bubu tradisional juga digunakan batangnya untuk menikam ikan, sementara tiga jenis rotan yaitu Calamus interuptus Becc. (Ses), Calamus keyensis Becc. (Bofake) dan Korthalsia zippelii Burr. (Hiyoh) merupakan bahan pelengkap dalam pembuatannya. Purwanto (2005) menjelaskan bahwa perilaku sosial budaya menghubungkan berbagai faktor yang kompleks dan dalam prosesnya ditentukan oleh karakteristik dan keragaman biofisik lingkungan tempat tinggalnya.

Berdasarkan pengamatan di lapangan bahwa jenis Hydriastele pinangoides Becc. W. J. Baker \& Loo. (Srah), Calamus interuptus Becc. (Ses) dan Korthalsia zippelii Burr. (Hiyoh) merupakan jenis palem yang digunakan secara turun-temurun karena memiliki bentuk batang yang kuat, ringan, tahan lama dan tahan terhadap air sehingga masyarakat memilih untuk menggunaan jenis tersebut dalam pembuatan bubu dari generasi ke genarsi. Sementara untuk jenis Calamus keyensis Becc. (Bofake) adalah jenis pemilihan sekunder untuk bahan yang digunakan untuk pembuatan bubu tradisional jika jenis utama sulit diperoleh pada habitat alami hutan di sekitar pemukiman penduduk. Hal ini menunjukan bahwa sifat ketergantungan komunitas masyarakat lokal yang masih sangat tinggi terhadap SDA hutan.

Perubahan pengetahuan terkait kriteria dan pemilihan bahan baku dalam pembuatan bubu tradisional terkait pula dengan perubahan lingkungan ekologi habitat hutan dan perubahan sosial masyarakat suku Maybrat. Hal ini didukung hasil kajian tentang degradasi habitat hutan di sekitar danau Ayamaru 
(Hismayasari dkk. 2015) menyebabkan makin sulitnya diperoleh bahan pembuatan bubu. Selain degradasi lingkungan hutan sebagai habitat palem, juga terjadi perubahan sosial dalam masyarakat dalam menggunakan jenis Calamus keyensis Becc. (Bofake) sebagai pengganti jenis Calamus interuptus Becc. (Bomifra) adalah masyarakat yang pekerjaan utamanya sebagai nelayan atau yang disebut orang danau. Hal tersebut disebabkan kebutuhan ekonomi yang mendesak dan efisiensi sehingga masyarakat terpaksa memilih jenis yang terdekat dan lebih mudah peroleh di pulau-pulau kecil khusunya di sekitar danau jika dibandingkan ke hutan yang jaraknya cukup jauh. Dalam perkembangannya jenis Calamus interuptus Becc. (Ses) dan Korthalsia zippellii Burr. (Hiyoh) telah digantikan dengan bahan yang lain dengan penggunaan tali yang terbuat dari plastik karena kemudahan mendapatkannya dengan cara dibeli dari toko atau pasar.

\section{Etnoteknokonservasi Pembuatan Bubu oleh Suku Maybrat}

Sejak awalnya lingkungan habitat hutan alam di sekitar danau Ayamaru merupakan bagian penting dari proses terbentuknya sistem pengetahuan pemanfaatan palem untuk pembuatan bubu tradisinal. Potensi lingkungan alam dapat mempengaruhi cara bagaimana sistem sumberdaya alam digunakan, demikian juga sebaliknya sistem pemanfaatan dapat berpengaruh pada lingkunganya.

Konstruksi pengetahuan lokal pemanfaatan palem dalam pembuatan bubu tradisional pada suku Maybrat tidak tersebar merata dalam komunitas masyarakatnya. Berdasarkan hasil penelitian, umumnya masyarakat yang memiliki pengetahuan lokal ini berasal dari masyarakat yang hidup bermukim di seputaran
DAS dan danau Ayamaru terkait dengan profesi nelayan sebagai mata pencaharian utama ataupun sampingan. Hal ini sesuai dengan Berkes (1999) bahwa pengetahuan lokal bersumber pula dari mata pencaharian utama mereka.

Pemanfaatan bubu sangat penting bagi Masyarakat Kampung Mapura khususnya masyarakat yang berprofesi utama sebagai nelayan. Pemanfaatan bubu oleh masyarakat Kampung Mapura adalah sebagai alat untuk penangkapan ikan dalam memenuhi kebutuhan hidup subsisten dan dapat dijual membantu dalam perekonomian keluarga. Penting dalam kajian ini adalah mengkonstruksikan pengetahuan suku Maybrat mulai dari tahap awal proses hingga akhir hasilnya digunakan untuk menangkap ikan. Tahapan proses deskripsi ini dianggap penting karena literasi budaya menulis yang kurang pada masyarakat Papua sehingga banyak nilai-nilai kearifan lokal yang hilang di dalamnya.

Dalam kajian ini konstruksi etnotenokonservasi pengetahuan lokal masyarakat Kampung Mapura dalam pembuatan anyaman bubu disebut dengan $M j i$ Wata. Proses kontruksi pembuatan anyaman bubu dilakukan dalam dua tahapan secara terpisah yaitu anyaman bubu (Wata) dan anyaman penutup bubu (Watmaku). Dalam proses anyaman bubu digunakan 3 (tiga) jenis palem yaitu Srah, Bomifra dan Bosin, sementara dalam proses anyaman penutup digunakan 2 (dua) jenis palem yaitu Bomifra dan Bosin. Jenis-jenis tersebut telah digunakan oleh masyarakat Kampung Mapura secara turun-temurun.

Proses pembuatan bubu oleh masyarakat Kampung Mapura dilakukan dengan menggunakan teknik secara tradisional dengan menggunakan alat sederhana dan dilakukan 
dalam beberapa tahapan dimulai dari proses: (1) pengambilan,

(2) pembersihan, pemotongan,

(4) pengangkutan, pembelehan, (6) pengikisan, (7) penganyaman bubu (8) penganyaman penutup bubu (9) penangkapan ikan menggunakan bubu. Secara singkat tahapan proses pemanfaatan palem dalam pembuatan bubu tradisional suku Maybrat dapat dilihat pada Gambar 4.
Gambar 4. Proses pengetahuan pembuatan bubu suku Maybrat

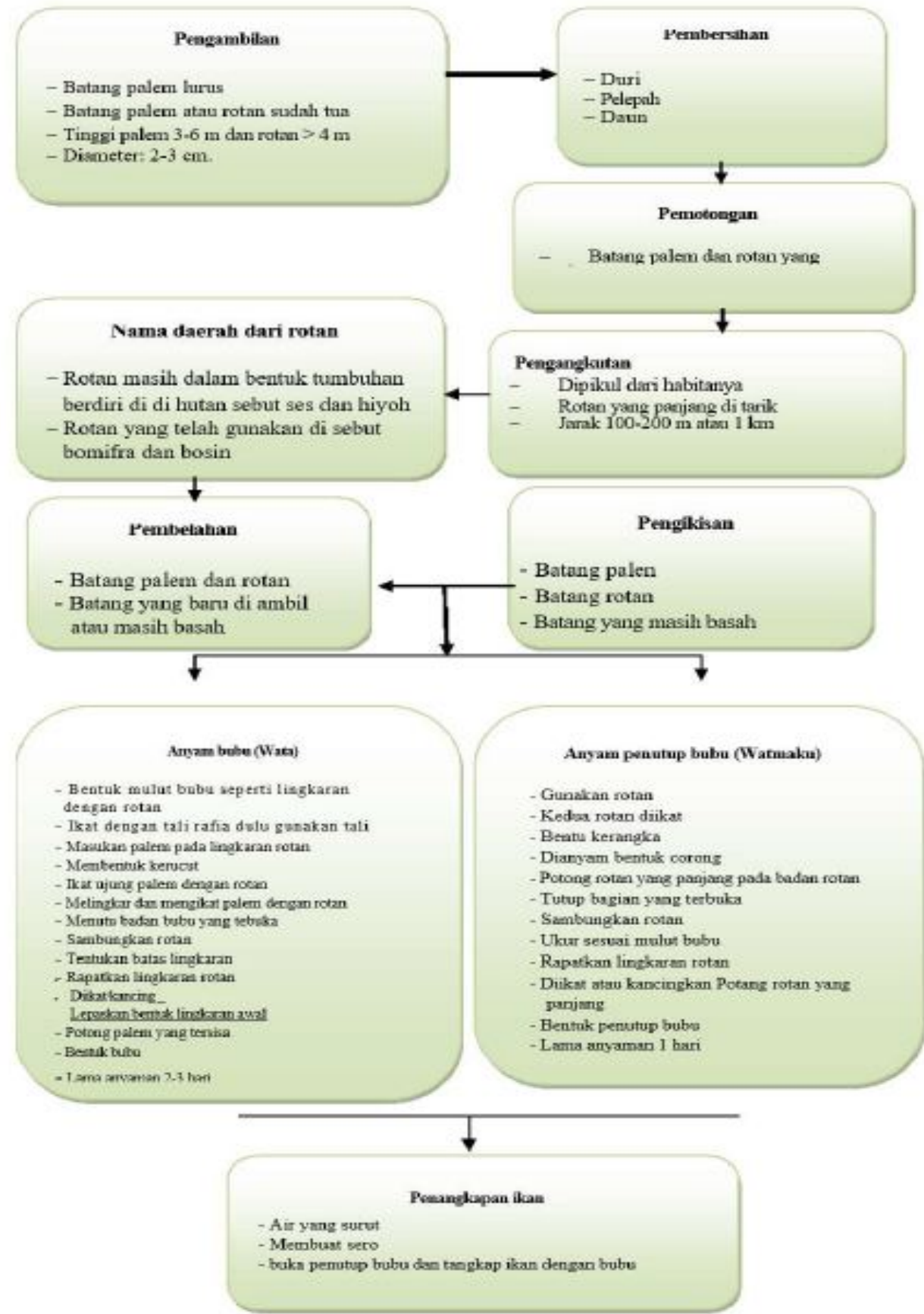


Tapan pengetahuan lokal yang berkenaan dengan pemanfaatan tumbuhan palem dan lingkungan fisiknya pertama dimulai dari proses pengambilan tumbuhan palem berdasarkan pada kriteria pemilihan jenis yang telah digunakan oleh masyarakat secara turuntemurun. Pemilihan tumbuhan palem yang sudah tua, bentuk batang palem yang lurus, tinggi palem 3-6 meter, diameter palem $2-3 \mathrm{~cm}$ dan panjang rotan $>4$ meter. Tujuan agar dalam proses pembuatan bubu, tumbuhan palem yang dimanfaatkan dapat bertahan lama dan tidak mudah patah/rusak. Dibutuhkan jumlah tumbuhan yang berbeda karana tumbuhan palem memiliki ukuran yang tidak sama untuk pembuatan bubu. Bubu berukuran besar menggunakan 10-20 batang palem dan 1-2 batang rotan, 5-7 batang palem dan 1-2 batng rotan untuk bubu berukuran sedang dan 3-5 batang palem dan 1 rotan untuk bubu berukuran kecil.

Tahap kedua adalah proses pembersihan tumbuhan palem pada bagian daun, tangkai daun, pelepah dan duri dengan menggunakan parang. Hal ini dilakukan karena bagian-bagian dari tumbuhan palem tersebut tidak dimanfaatkan hanya bagian batang dari tumbuhan palem yang dibutuhkan. Selain itu proses pembersihan dilakukan agar pengangkutan dari hutan ke rumah lebih mudah. Tahap ketiga adalah proses pemotongan batang palem agar memudahkan dalam pengangkutan. Pemotongan batang palem bisa dilakukan di hutan maupun di rumah. Batang palem memiliki tinggi mencapai 5-6 meter sehingga masyarakat melakukan pemotong menjadi dua bagian untuk digunakan dalam pembuatan bubu.

Tahap keempat adalah pengangkutan. Pengangkutan tumbuhan palem yang digunakan untuk pembuatan bubu dilakukan dengan cara dipikul berjalan kaki. Hal ini dikarenakan jarak tempuh dari hutan untuk sampai ke rumah tidak begitu jauh, hanya mencapai 100-200 meter. Pengangkutan tumbuhan palem untuk sampai di rumah, juga dapat ditempuh dengan jarak $1 \mathrm{~km}$ untuk jenis-jenis palem tertentu yang tumbuh sangat jauh dari kampung. Untuk jenis rotan yang panjang dapat diangkut dengan cara ditarik keluar dari hutan. Proses tahapan pertama sampai kelima dapat dilihat pada Gambar 5.

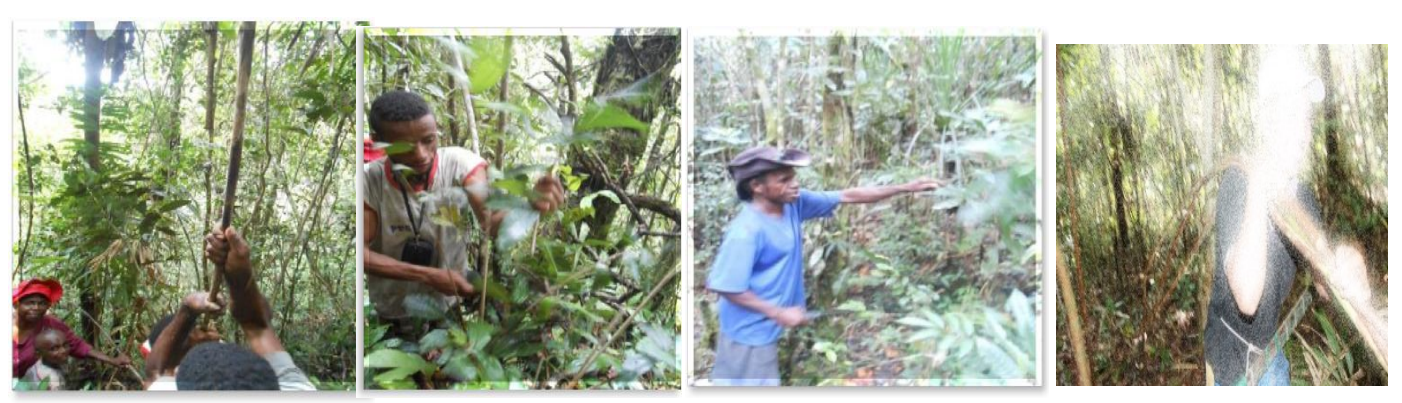

Gambar 5. Tahapan pertama sampai keempat

Pada tahap pertama dan keempat secara umum aktifitas pemanfaatan berlangsung di alam atau pada habitat palem di hutan sebagai lokasi pengambilan bahan baku pembuatan bubu. Aktivitas ini dilakukan oleh masyarakat dari kelas umur anak, pemuda dan orang tua dapat dilakukan bersama. Peralatan sederhana yang digunakan adalah parang dilakukan secar mekanis menggunakan tenaga manusia. 
Tahap kelima adalah proses pengikisan batang palem setelah dilakukan proses pembelahan menjadi beberap bagian. Proses pengikisan dilakukan secara bertahap dengan menggunakan pisau. Proses ini dilakukan di halaman rumah, sama halnya dengan proses pembelahan agar mudah dalam melakukan pengikisan, karena batang palem mempunyai ukuran relatif masih panjang. Dalam proses pengikisan dibutuhkan waktu selama 20-30 menit dan dilakukan dengan sangat teliti sehingga tidak merusak batang palem tersebut, apabila batang palem rusak, maka akan digantikan dengan yang baru.

Tahap keenam adalah pembelahan batang palem menjadi beberapa bagian. palem menjadi beberapa bagian. Proses pembelahan palem dilakukan tanpa harus melakukan perlakuan proses pengeringan batang terlebih dahulu. Berdasarkan pengalaman masyarakat bahwa tumbuhan palem yang masih basah lebih mudah untuk dilakukan pembelahan dan mudah untuk dibentuk dalam pembuatan bubu dibandingkan yang sudah kering. Pembelahan batang palem untuk tiap jenis berbeda hasilnya antara 4-6 bagian. Untuk pembelahan 1 batang Srah yang ukurannya lebih besar dapat diperoleh 4-6 bagian, sementara untuk batang Bomifra dan Bosin dapat diperoleh 2-4 bagian. Proses tahap kelima dan keenam dapat dilihat pada Gambar 6.
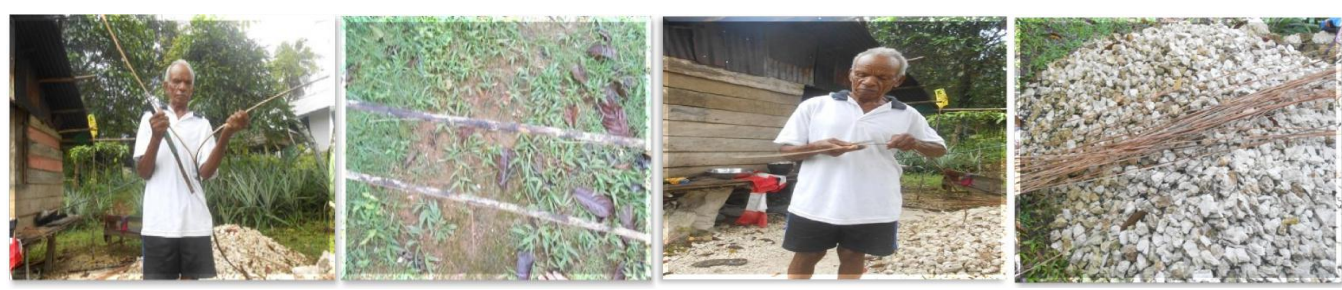

Gambar 6. Tahapan kelima dan enam

Pada tahap kelima dan keenam aktivitas sudah dilakukan pada lingkungan pemukiman atau rumah masyarakat. Pada aktivitas pembelahan dan pembersihan jenis tumbuhan palem telah diambil dari hutan selanjutnya oleh orang tua dan dibantu anak muda akan mempersiapkannya sebagai bahan utama pembuatan konstruksi bubu. Alat yang digunakan adalah sebilah pisau kecil yang tajam untuk membelah dan mengikis menjadi potongan kecil sebagai bahan penganyaman bubu.

Tahapan ketujuh dalam penganyaman bubu dimulai dengan pemmbuatan mulut bubu membentuk lingkaran/bulatan dengan menggunakan Bomifra dan diikat menggunakan tali agar lingkaran tersebut menjadi kuat.
Dahulu masyarakat menggunakan tali dari hutan atau tali dari jenis rotan yang digunakan untuk pembuatan bubu tersebut. Berdasarkan pengamatan bahwa masyarakat telah menggunakan tali yang dibuat dari plastik untuk mengikat bentuk lingkaran yang dibuat. Bentuk lingkaran tersebut dibuat sementara sebagai rangka awal dari mulut bubu untuk memasukan Srah sehingga membentuk kerucut. Tetapi setelah selesai dalam menganyam bubu, maka rangka awal tersebut akan dilepas karena hanya membantu dalam menahan Srah yang dimasukan.

Tahap kedelapan pembuatan anyaman untuk penutup bubu dapat dilakukan dengan membuat rangka terlebih dahulu menggunakan Bomifra dan Bosin. Berdasarkan pengamatan di 
lapangan bahwa anyaman penutup bubu dapat dilakukan dengan mengikat Bomifra dan Bosin menjadi satu bagian dan ditahan menggunakan kaki. Hal tersebut dilakukan agar kedua ikatan tersebut tidak terlepas. Selanjutnya Bomifra dimasukan melalui Bosin dan diikat dengan Bosin. Proses tersebut dilakukan secara tersusun agar dapat berbentuk menjari.

Tahap ketujuh dan kedelapan adalah proses terpenting dengan tingkat kesulitan dan kerumitan pembuatan sehingga diperlukan waktu yang relatif lama. Umumnya skil atau keterampilan ini sangat terbatas dimiliki dalam komunitas suku Maybrat dan dominan dikuasai oleh kelas umur orang tua. Tahapan tujuh, delapan dan sembilan dapat dilihat pada Gambar 7.
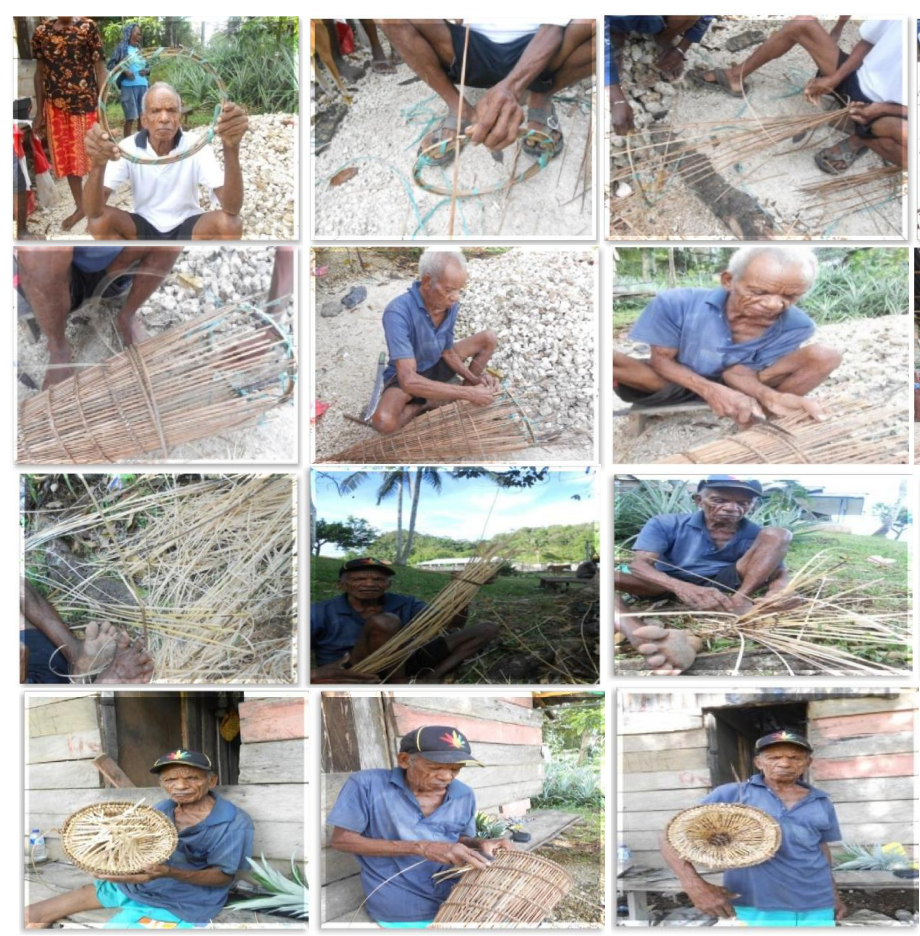

Gambar 7. Tahapan proses penganyaman dan pemasangan bubu

Tahapan proses penganyaman dan pemasangan bubu adalah proses inti dalam konstruksi etnoteknokonservasi. Pengetahuan lokal yang dimiliki oleh suku Maybrat dalam proses ini sangat bergantung pada invidu yang secara umum hanya dimiliki oleh kelas umur orang tua. Pengetahuan teknik membuat bubu dan memasang bubu hanya dimiliki oleh mereka yang bermata pencaharian sebagai nelayan. Namun tidak semua nelayan memiliki pengetahuan dan teknik membuat bubu. Bubu yang digunakan diperoleh dengan cara transaksi membeli atau menukar dengan barang berharga lainnya.

Konservasi pemanfaatan palem oleh suku Maybrat dapat dilihat pada sistem penangkapan ikan yang ramah lingkungan. Konteksnya adalah hubungan antara perilaku hidup manusia dengan lingkungan disebut

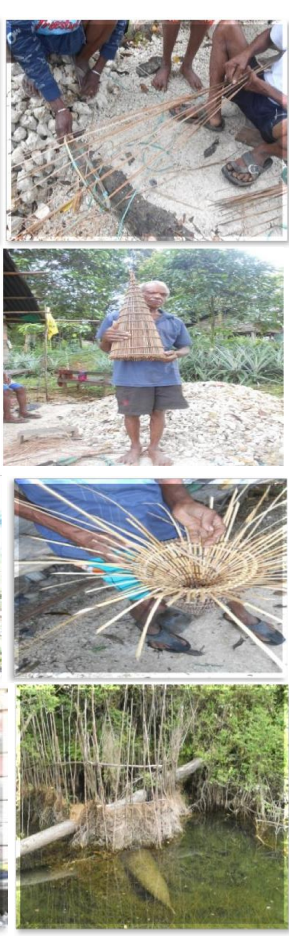
sebagai environmental determinism. Teknik yang unik tersebut dapat dilihat dari sistem pengetahuan pemasangan bubu di sungai atau danau. Pemasangan bubu yang digunakan untuk menangkap ikan dengan teknik membuat sero. Keterampilan ini tergolong dalam kecakapan hidup (life skill) sangat bergantung pada kondisi geografis dan biofisik lingkungan tempat tinggal serta intensitas interaksi dengan hutan (Ungirwalu dkk. 2018).

$\begin{array}{cc}\text { Sero adalah teknik } \\ \text { tradisional } & \text { ramah }\end{array}$

lingkungan yang dibuat untuk pemasang bubu menggunakan bahan yang berasal dari sekitar lokasinya. Pembuatan sero dilakukan oleh 1-2 orang (umunya laki-laki) dengan memasang kayu secara berpasangan berbentuk segitiga 
atau segi empat dengan pembatas menggunakan rumput danau yaitu Eragrostis sp. (Wohara). Pemasangan bubu pada sero dibuat berlawanan arus air, kemudian disanggah oleh kayu pada kedua sisi bubu sebagai penahan dan kemudian ditutup tumpukan rumput di atasnya. Teknik ini sudah dilakukan secara turun-temurun sebagai salah satu bagian dari pemanfaatan SDA berkalanjutan. Pengetahuan lokal pembuatan bubu dan teknik pembuatan sero suku Maybrat adalah bagian dari simbol kognitif (cognitive symbol) sama dengan suku bangsa lainnya (Rudito dan Famiola 2008; Ungirwalu dkk. 2017). Sayangnya pengetahuan ini semakin tergerus oleh perkembangan ilmu, pengetahuan dan teknologi yang berasal dari luar komunitas suku Maybrat.

\section{KESIMPULAN}

Ketergantungan komunitas masyarakat lokal terhadap potensi SDA hutan sampai saat ini masih sangat tinggi. Terbukti dari penggunaan tumbuhan palem yang digunakan oleh Suku Maybrat dalam pembuatan bubu tradisional adalah bersumber dari lingkungan hutan dan sekitarnya di danau Ayamaru. Berdasarkan hasil pelingkupan pengetahuan lokal pembuatan bubu dan teknik pembuatan sero suku Maybrat adalah bagian dari simbol kognitif yang tergolong dalam kecakapan hidup (life skill) individu dimana kondisinya sangat bergantung pada keadaan lingkungan tempat tinggal dan potensi sumberdaya hutan yang dimilikinya. Pemanfaatan tumbuhan palem sebagai sumberdaya alam dan proses konstruksi pengetahuan lokal pembuatan bubu tradisional sebagai wujud etnoteknokonservasi suku Maybrat berkaitan erat dengan mata pencaharian masyarakt sebagai nelayan aktif dan pasif. Pengetahuan lokal dalam pemanfaatan tumbuhan palem dalam proses pembentukannya tidak sekedar berdimensi kognitif semata, tetapi juga berdimensi nilai konservasi lokal dalam mempertahankan sistem penagkapan ikan yang ramah lingkungan dan berkelanjutan. Perubahan sosial dan lingkungan adalah tantangan terbesar, terutama ekspansi ilmu, pengetahuan dan teknologi (IPTEK) dari luar komunitas serta penerapan kebijakan yang tidak ramah lingkungan dan budaya sehingga berdampak pada degradasi lingkungan dan pengetahuan lokal masyarakatnya.

\section{UCAPAN TERIMA KASIH}

Terimakasih kepada pemerintah daerah Kabupaten Maybrat dan masyarakat Kampung Mapura Distrik Ayamaru Utara Timur atas kerjasama selama penelitian serta semua pihak yang tidak disebutkan satu persatu atas kontribusinya hingga tulisan ini dapat dilengkapi dengan data pendukung dan gambar yang komperhensif. Pada akhir ucapan ini kami ingin menyampaikan terimakasih kepada para reviewer yang sudah berkenan memeriksa paper ini.

\section{DAFTAR PUSTAKA}

Albuquerque UP et al. 2018. Humans as niche constructors: Revisiting the concept of chronic anthropogenic disturbances in ecology. Perspectives in Ecology and Conservation. 16(1): 1-11. doi: 10.1016/j.pecon.2017.08.006.

Asmuruf A. 2002. Pemanfaatan nipah (Nypa fruticans Wurmb) oleh lima suku di Bintuni. [Skripsi]. Jurusan Kehutanan Fakultas Pertanian Universitas Negeri Papua, Manokwari.

Balick MJ. 1996. Transforming ethnobotany for the New Millennium. Annals of the Missouri Botanical Garden. 83(1): p. 58. doi: 


\section{$10.2307 / 2399968$}

Barrera-bassols AN, Toledo VM. 2013. Ethnoecology of the Yucatec Maya: Symbolism, Knowledge and Management of Natural Resources All use subject to JSTOR Terms and Conditions Ethnoecology Natural of the Yucatec Resources Symbolism, Knowledge Maya: and Management of. Journal of Latin American Geography. 4(1): 9-41.

Berkes F. 2009. Evolution of co-management: Role of knowledge generation, bridging organizations and social learning. Journal of Environmental Management. 90(5): 16921702. doi: 10.1016/j.jenvman.2008.12.001.

Cámara-Leret $\mathrm{R}$ et al. 2014. Ethnobotanical knowledge is vastly under-documented in northwestern South America. PLoS ONE. 9(1). doi: 10.1371/journal.pone.0085794.

Cámara-Leret R, Dennehy Z. 2019. Information gaps in indigenous and local knowledge for science-policy assessments. Nature Sustainability. 2(8): 736-741. doi: 10.1038/s41893-019-0324-0.

Dako FX et al. 2019. Community's social capital in the management of Mutis Timau protected forest in Timor island, Indonesia. Biodiversitas. 20(8): 2177-2187. doi: 10.13057/biodiv/d200811.

Damayanti SY, Syahrani A. 2018. Teks adalah satuan bahasa yang digunakan sebagai ungkapan suatu kegiatan sosial baik secara lisan maupun tulis dengan struktur berpikir yang lengkap (Mahsun, 2014: 1). Jurnal Pendidikan dan Pembelajaran Khatulistiwa. 7 (9).

Dharmono. 2007. Kajian etnobotani tumbuhan julakap (Centella asiatica L.) di suku Dayak bukit desa Haratai 1 Laksado. Bioscientie. 4(2):71-78.

Forster PI. 1993. The Synonymy of
Anodendron paniculatum (Apocynaceae) with Notes on Distribution and Ethnobotany in Papuasia Authors (s): Paul I . Forster Published by: Springer on behalf of Royal Botanic Gardens, Kew Stable URL: http://www.jstor.org/stable/4115758. Kew Bulletin. 48(1): 139-142.

Hismayasari IB, Rahayu S, Marhendra APW. 2015. Ovary maturation stages histology and follicles diameter of Melanotaenia boesemani rainbowfish ovary from district of North Ayamaru, Maybrat Regency, West Papua. Journal of Morphological Sciences. 32(3): 157-164. doi: 10.4322/jms.082914.

Joa B, Winkel G, Primmer E. 2018. The unknown known - A review of local ecological knowledge in relation to forest biodiversity conservation. Land Use Policy. 79(May): $\quad 520-530 . \quad$ doi: 10.1016/j.landusepol.2018.09.001.

Mansai YY. 2003. Pemanfaatan palem oleh etnik Randawaya di Pulau Yapen. [Skripsi]. Fakultas Kehutanan Universitas Negeri Papua, Manokwari.

Matubongs RA, Arobaya AYS, Yan RP. 1996. Etnobotany of Tepin tribe in Salawati Island in Sorong Regency Irian Jaya Manokwari.

Powell JM. 1976. Ethnobotany. New Guinea Vegetation. 106-183.

Rudito B, Famiola M. 2008. Metoda pemetaan sosial. Rekayasa Sains. Bandung.

Rumbiak WF. 2000. Pemanfaatan palem oleh masyarakat etnik wondama di desa Tandia kecamatan Wasior kabupaten Manokwari. [Skripsi]. Jurusan Kehutanan Universitas Negeri Cendrawasih, Manokwari.

Roslinda E. 2018. Social capital of the community in the management of Danau Sentarum National Park, West Kalimantan, Indonesia. Biodiversitas. 19(4): 1249-1257. doi: 10.13057/biodiv/d190410. 
Sardjono dan Mustofa A. 2004. Mozaik sosiologi kehutanan: Masyarakat lokal, politik dan kelestarian sumberdaya. Yogyakarta: Debut Press. Yogyakarta.

Ungirwalu A et al. 2017. The ethno-technoconservation approach in the utilization of black fruit (Haplolobus sp.) by the Wandamen ethnic of Papua, Indonesia.
Biodiversitas. 18(4): 2085-4722. doi: 10.13057/biodiv/d180408.

Ungirwalu A, Awang SA, Tokede MJ. 2018. Etnobotani buah hitam: Konstruksi etnoekologi etnis Wandamen Papua. Penerbit Deepublish, Jl. Kaliurang, Yogyakarta. 